\title{
Inhibition by glucose or leptin of hypothalamic neurons expressing neuropeptide $Y$ requires changes in AMP-activated protein kinase activity
}

\author{
P. D. Mountjoy • S. J. Bailey • G. A. Rutter
}

Received: 10 July 2006 / Accepted: 4 September 2006 / Published online: 9 November 2006

(C) Springer-Verlag 2006

\begin{abstract}
Aims/hypothesis Changes in the activity of glucose-excited and glucose-inhibited neurons within the basomedial hypothalamus are key to the central regulation of satiety. However, the molecular mechanisms through which these cells respond to extracellular stimuli remain poorly understood. Here, we investigate the role of 5'-AMP-activated protein kinase (AMPK), a trimeric complex encoded by seven distinct genes of the PRKA family, in the responses to glucose and leptin of each cell type.

Methods The activity of isolated rat basomedial hypothalamic neurons was assessed by: (1) recording cellular voltage responses under current clamp; (2) measuring intracellular free $\mathrm{Ca}^{2+}$ with fluo-3 or fura-2; and (3) developing a neuropeptide Y (NPY) promoter-driven adenovirally pro-
\end{abstract}

Electronic supplementary material Supplementary material is available in the online version of this article at http://dx.doi.org/ $10.1007 / \mathrm{s} 00125-006-0473-3$ and is accessible to authorised users.

P. D. Mountjoy $\cdot$ S. J. Bailey $\cdot$ G. A. Rutter $(\bowtie)$

Henry Wellcome Laboratories of Integrated Cell Signalling

and Department of Biochemistry, School of Medical Sciences,

University of Bristol,

Bristol, UK

e-mail: g.rutter@imperial.ac.uk

Present address:

G. A. Rutter

Department of Cell Biology, Division of Medicine,

Faculty of Medicine, Sir Alexander Fleming Building,

Exhibition Road, Imperial College London,

London, UK

Present address:

S. J. Bailey

Department of Pharmacy and Pharmacology,

University of Bath,

Bath, UK duced ratiometric 'pericam' (a green fluorescent proteinbased $\mathrm{Ca}^{2+}$ sensor) to monitor $\left[\mathrm{Ca}^{2+}\right]$ changes selectively in NPY-positive neurons.

Results The stimulatory effects of decreased ( 0 or 1.0 vs $15 \mathrm{mmol} / \mathrm{l})$ glucose on glucose-inhibited neurons were mimicked by the AMPK activator, 5-amino-imidazole-4carboxamide riboside (AICAR) and blocked by the inhibitor Compound C. Similarly, AICAR reversed the inhibitory effects of leptin in the majority of glucose-inhibited neurons. The responses to glucose of $N p y$-expressing cells, which represented $\sim 40 \%$ of all glucose-inhibited neurons, were also sensitive to Compound $\mathrm{C}$ or AICAR. Forced changes in AMPK activity had no effect on glucose-excited and non-glucose-responsive neurons.

Conclusions/interpretation Changes in AMPK activity are involved in the responses of glucose-inhibited neurons to large fluctuations in glucose concentration, and possibly also to leptin. This mechanism may contribute to the acute reduction of electrical activity and $\mathrm{Ca}^{2+}$ oscillation frequency in these, but not other neurons, in the basomedial hypothalamus.

Keywords AMPK · GE · GI · Glucose-excited . Glucose-inhibited · Hypothalamus · Leptin · Neurons .

Neuropeptide Y.PRKA $\cdot$ Satiety
Abbreviations
AICAR 5-amino-imidazole-4-carboxamide riboside
AMPK 5'-AMP-activated protein kinase
$\left[\mathrm{Ca}^{2+}\right]_{\mathrm{c}}$ cytosolic free $\mathrm{Ca}^{2+}$ concentration
GE glucose-excited
GFP green fluorescent protein
GI glucose-inhibited
$\mathrm{K}_{\mathrm{ATP}} \quad$ ATP-sensitive potassium
NPY neuropeptide Y 
POMC proopiomelanocortin

WPRE woodchuck hepatitis virus post-transcriptional regulatory element

\section{Introduction}

Clinical obesity, an important risk factor for the development of type 2 diabetes, now affects approximately $30 \%$ of the US and $20 \%$ of the UK adult populations $[1,2]$. Currently, however, the behavioural and physiological cues leading to imbalanced food intake and energy expenditure remain poorly defined.

Neurons of the hypothalamic arcuate nucleus that express neuropeptide $\mathrm{Y}-(\mathrm{Npy})$ and agouti-related peptide genes, or proopiomelanocortin (Pomc) and cocaine-amphetamine-regulated transcript genes, have been identified as key components of the regulatory mechanism which operates centrally to control satiety $[1,3]$. These neurons are targeted by several appetite-regulating hormones, including leptin [3-6] and ghrelin [7, 8]. In addition, changes in circulating blood glucose concentration also exert direct effects on neurons within this region. Thus, both glucose-excited (GE) and glucose-inhibited (GI) neurons have been identified [9-13], and are proposed to overlap, at least in part, with the Pomc-and Npy-expressing populations respectively.

The presence in GE neurons of glucokinase $[14,15]$ and of ATP-sensitive potassium $\left(\mathrm{K}_{\text {ATP }}\right)$ channels $[11,15]$ has led to the proposal that these cells sense changes in the concentration of glucose via a mechanism analogous to that which operates in pancreatic beta cells [16], involving enhanced oxidative metabolism and mitochondrial ATP synthesis. However, glucose-induced changes in free ATP concentrations appear to be far smaller in hypothalamic neurons than in pancreatic beta cells [17], suggesting that distinct glucose signalling mechanisms occur in GE neurons. On the other hand, there is little consensus as to the mechanisms by which GI neurons are activated by falling glucose concentrations $[13,14]$.

In this report, we examine the potential involvement of 5'-AMP-activated protein kinase (AMPK), an enzyme dubbed the 'fuel gauge' of the mammalian cell $[18,19]$. Changes in AMPK activity were recently implicated in the control of food intake in living rodents [20,21], although neither the neuronal cell types, nor the events downstream of AMPK activation, were explored in these earlier studies.

Through single cell imaging of intracellular cytosolic free $\mathrm{Ca}^{2+}$ concentrations $\left(\left[\mathrm{Ca}^{2+}\right]_{\mathrm{c}}\right)$ and measurement of plasma membrane potential, we show that decreases in AMPK activity mimic, and increases in AMPK activity block the effects of glucose and leptin on hypothalamic GI, but not on GE neurons. By developing a neuropeptide $\mathrm{Y}$ promoter-driven adenovirally produced ratiometric-'pericam' (a green fluorescent protein [GFP]-based $\mathrm{Ca}^{2+}$ sensor) [22], we show that the responses of $N p y$-expressing neurons to glucose require changes in AMPK activity. AMPK is thus identified as a possible intracellular mediator of the acute effects of satiety factors on GI neurons.

\section{Materials and methods}

Materials We obtained 5-amino-imidazole-4-carboxamide riboside (AICAR) from Toronto Research Chemicals, Toronto, ON, Canada. Compound $\mathrm{C}$ was a kind gift from M. Van de Casteele (Diabetes Research Centre, Brussels, Belgium), with permission from Merck Research Laboratories (Rahway, NJ, USA). Tolbutamide and recombinant mouse leptin were from Sigma (Poole, Dorset, UK). All other reagents were from Sigma or BDH (Poole, Dorset, UK).

Isolation and culture of hypothalamic neurons Wistar rat pups, postnatal day 2 to 4 (three per preparation; University of Bristol Medical School breeding facility), were killed by cervical dislocation (in accordance with local ethics committee guidelines). Following decapitation and removal of the brain, the basomedial region of the hypothalamus was isolated and neurons dissociated in HEPES-buffered saline comprising (mmol/l): $\mathrm{NaCl} 130, \mathrm{KCl} 5.4, \mathrm{CaCl}_{2} 1.8$, $\mathrm{MgCl}_{2}$ 1, HEPES 10, glucose 3, pH 7.4, as described in detail previously [17]. Cells were resuspended in modified Eagle's medium (glucose $5 \mathrm{mmol} / \mathrm{l}$; Invitrogen Life Technologies, Paisley, UK) supplemented with $5 \%(\mathrm{v} / \mathrm{v})$ fetal bovine serum (Invitrogen Life Technologies), 5\% horse serum (Invitrogen Life Technologies), $2 \mathrm{mmol} / 1$ glutamine, $5 \mu \mathrm{g} / \mathrm{ml}$ insulin (Sigma), $50 \mathrm{pg} / \mathrm{ml}$ fibroblast growth factor (Sigma), $5 \mathrm{mmol} / \mathrm{l}$ HEPES, $10 \mu \mathrm{g} / \mathrm{ml}$ penicillin and $10 \mu \mathrm{g} / \mathrm{ml}$ streptomycin, and spotted on to poly-L-lysine-coated glass-bottomed culture dishes $(35 \mathrm{~mm}$ diameter; MaTek Corporation, Ashland, MA, USA), before being left to adhere for $1 \mathrm{~h}$ at $37^{\circ} \mathrm{C}$ in a humidified incubator at $5 \% \mathrm{CO}_{2}$. The medium was then changed to Neurobasal medium (glucose $25 \mathrm{mmol} / \mathrm{l}$; Invitrogen Life Technologies) supplemented with $\mathrm{N}_{2}$ serum (Invitrogen Life Technologies), $2 \mathrm{mmol} / \mathrm{l}$ glutamine, $10 \mu \mathrm{g} / \mathrm{ml}$ penicillin and $10 \mu \mathrm{g} / \mathrm{ml}$ streptomycin. After approximately 5 days, arabinosylcytosine ( $5 \mu \mathrm{mol} / \mathrm{l}$, Ara-C; Sigma) was added to prevent overgrowth of glial cells, and experiments were performed 5 to 8 days after isolation [17].

Generation of NPY-ratiometric-pericam recombinant adenovirus A fragment of the pXCX.Syn1.EGFP vector, a 
kind gift from J. Uney (Laboratories for Integrative Neurosciences and Endocrinology, University of Bristol, UK) [23], containing the woodchuck hepatitis virus post-transcriptional regulatory element (WPRE), was amplified by

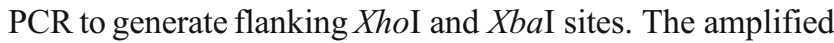
fragment was then ligated into pCR2.1 (Invitrogen Life Technologies) to generate plasmid pCR2.1.WPRE.pA.

pCR2.1.WPRE.pA and the pShuttle vector from the pAdEasy adenovirus generation system [24] were digested with $X b a \mathrm{I}$ and $X h o \mathrm{I}$, and the liberated WPRE.pA fragment ligated into pShuttle, giving pShuttle.WPRE.pA. A BamHI$X b a \mathrm{I}$ ratiometric-pericam fragment from pcDNA3.ratiometric-pericam [22] was cloned downstream of a 700-bp region of the NPY promoter in pNPY.luciferase [25], forming pNPY.ratiometric-pericam.

An XbaI-HindIII fragment released from pNPY.ratiometric-pericam was then ligated into pShuttle.WPRE.pA to generate pShuttle.NPY.ratiometric-pericam.WPRE.pA, and adenoviruses generated using the AdEasy system [24, 26]. Amplified adenoviruses were subsequently purified using CsCl-gradient centrifugation $(\sim 372,000 \mathrm{~g})$ overnight at $4^{\circ} \mathrm{C}$.

Adenoviral infection Primary hypothalamic neuronal cultures (cultured for 4 days after isolation) were incubated with purified adenovirus overnight. Fresh neurobasal medium was then added and the cells cultured for a further $48 \mathrm{~h}$ in the absence of virus before being used.

Imaging cytosolic free $\mathrm{Ca}^{2+}$ concentration Cells were loaded with $5 \mu \mathrm{mol} / 1$ fluo-3 or fura-2 (Sigma) for $20 \mathrm{~min}$ at $37^{\circ} \mathrm{C}$ in a solution consisting of (mmol/l): $\mathrm{NaCl} 140, \mathrm{KCl} 5, \mathrm{MgCl}_{2}$ $1.2, \mathrm{CaCl}_{2} 2$, HEPES $10(\mathrm{pH} 7.4)$ at $37^{\circ} \mathrm{C}$ plus glucose at the concentration in which recording commenced (indicated in the Figures). Fluorescence was measured by conventional epifluorescence microscopy using an inverted microscope (Olympus IX-70; Olympus, Southall, Middlesex, UK) and an illumination system (Till Photonics, Munich, Germany) ( $\times 40$ oil-immersion objective; Olympus U-APO/340, numerical aperture $=1.35 ; 490 \mathrm{~nm}$ dichroic mirror). Excitation at 340 and $380 \mathrm{~nm}$ for fura-2 $(10 \mathrm{~ms}$ exposure, 0.2 frames/s), 410 and $480 \mathrm{~nm}$ for ratiometric-pericam (15 or $20 \mathrm{~ms}$ exposure, 0.2 frames $/ \mathrm{s}$ ), or at $488 \mathrm{~nm}$ for fluo-3 (20 ms exposure, 0.2 frames/s) was achieved using a monochromator (Polychrome IV; Till Photonics). Emission at wavelengths $>515 \mathrm{~nm}$ was detected with an Imago SensiCam KL320 charge-coupled device camera (Till Photonics), and data acquisition was performed using TillVision software (Till Photonics) [27].

The apparent $\left[\mathrm{Ca}^{2+}\right]_{\mathrm{c}}$ responses of neurons were determined by calculating the AUC for changes in fluorescence (fluo-3) or fluorescence ratio (fura-2 and ratiometricpericam) after appropriate corrections for background and time-dependent dye loss/bleaching (fluo-3, $<5 \%$ in $40 \mathrm{~min}$ ).
AUC values were normalised to values in $1.0 \mathrm{mmol} / \mathrm{l}$ glucose (set at $100 \%$ ) as indicated in the figures.

Electrophysiology Whole-cell perforated patch recordings were made at 18 to $22^{\circ} \mathrm{C}$ using an amplifier (EPC9; HEKA Electronik, Lambrecht, Germany). Potentially glucoseresponsive cells were identified by monitoring $\left[\mathrm{Ca}^{2+}\right]_{\mathrm{c}}$ after loading cells with fluo-3 (at 0 or $1.0 \mathrm{mmol} / 1$ glucose). Fluorescent cells were imaged using a Photek ICCD (Photek, East Sussex, UK) imaging system attached to a Zeiss X-70 Axiovert inverted microscope $(\times 40$ objective; Carl Zeiss Microscopy, Welwyn Garden City, Herts, UK). All electrophysiology experiments began with cells held at low $(0$ or $1 \mathrm{mmol} / \mathrm{l})$ glucose concentrations. Borosilicate glass (Harvard Apparatus, Kent, UK) recording electrodes (resistance 3-6 M $\Omega$ ) were front-filled with an intracellular solution consisting of (mmol/l): potassium gluconate 130, $\mathrm{KCl} 10, \mathrm{MgCl}_{2} 0.1, \mathrm{CaCl}_{2}$ 0.05, EGTA-Na 3 0.5, HEPES 10 (an osmolarity of 295-310 mosmol/l was achieved by adjusting with sucrose; $\mathrm{pH}$ 7.2). Electrodes were then backfilled with intracellular fluid (composition as above) containing amphotericin B $(225 \mu \mathrm{g} / \mathrm{ml}$; Sigma $)$. The bath solution consisted of the following (mmol/l): $\mathrm{NaCl} 135$, $\mathrm{KCl} 5, \mathrm{CaCl}_{2} 1, \mathrm{MgCl}_{2}$ 1, HEPES 10 , glucose 1.0 or 15 (an osmolarity of 295-300 mosmol/1 was achieved by adjusting with sucrose; $\mathrm{pH}$ 7.4). Additions to the bath were made via the perifusion system.

Data were recorded in current clamp mode (continuous recording sample interval $10 \mathrm{kHz}$ ) using Pulse computer software (HEKA Electronik). Membrane potentials were set at $-55 \mathrm{mV}$ for each neuron before beginning continuous recording of action potentials in actual experiments.

Immunocytochemistry Cells were fixed in $4 \%(\mathrm{w} / \mathrm{v})$ paraformaldehyde and permeabilised with $0.2 \%$ Triton X-100, as described previously [28]. Incubation with primary antibodies $\left(4^{\circ} \mathrm{C}\right)$ overnight was as follows: rabbit antiAMPK-pan- $\alpha$ (1:400; Upstate, Milton Keynes, UK); sheep anti-AMPK- $\alpha 2$ (1:40), produced as described previously [27]; goat anti-NPY (1:50-1:200; Santa Cruz Biotechnology, Santa Cruz, CA, USA); and monoclonal mouse antiPOMC (1:500; a kind gift from R. Oliver, University of Manchester, UK). Treatment with secondary antibodies for 30 min was as follows: anti-goat alexa-568 (also used for the sheep primary antibody), anti-rabbit alexa-488, and anti-mouse alexa-568 (all 1:1,000; Invitrogen Life Technologies). Imaging was performed using a Leica TCS-NT confocal laser scanning microscope (Leica Microsystems, Milton Keynes, Bucks, UK) fitted with a $\times 40$ oil-immersion objective lens.

Statistical analysis Data are given as mean \pm SEM for the number of cells indicated, and statistical significance was 
calculated using ANOVA, followed by a Newman-Keuls test (Graphpad Prism; Graphpad Software, San Diego, CA, USA). Error bars in the figures show SEM for each condition and $* p<0.05,{ }^{* *} p<0.01, * * * p<0.001$. a

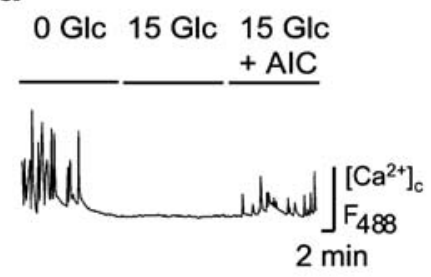

b

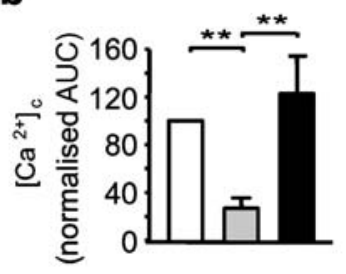

\section{Results}

Forced increases in AMPK activity reverse the inhibition by glucose of electrical activity and $\mathrm{Ca}^{2+}$ oscillations in GI neurons, but do not affect the activity of GE or non-glucose-responsive neurons Since the concentrations of glucose to which hypothalamic neurons are exposed remain controversial [29-31], we used here a range which covered or exceeded expected physiological fluctuations in this parameter $[12,17,29-32]$. Thus, transitions from 0 or 1.0 to $15 \mathrm{mmol} / \mathrm{l}$ glucose were chosen to identify glucosesensing neurons. Importantly, this was expected to allow neurons which respond to relatively high concentrations of glucose $(5-20 \mathrm{mmol} / \mathrm{l})$ [31] to be included in the study.

As in previous reports, changes in $\left[\mathrm{Ca}^{2+}\right]_{\mathrm{c}}$ were used as a convenient surrogate for the electrical activity of these cells $[14,17,33]$, although it is acknowledged that alterations in $\mathrm{Ca}^{2+}$ uptake and release from intracellular stores may contribute to the observed responses. GI neurons were identified as those in which a decrease in glucose concentration from 15 to 1.0 or $0 \mathrm{mmol} / \mathrm{l}$ led to an increase in $\left[\mathrm{Ca}^{2+}\right]_{\mathrm{c}}$ (determined as described in Materials and methods; Fig. 1a), while GE neurons were identified as those which showed a decrease in $\left[\mathrm{Ca}^{2+}\right]_{c}$ in response to this fall in glucose concentration (Fig. 1c).

In these experiments, $5 \%$ of neurons (nine out of 180 from seven separate preparations of fluo-3-loaded cells, and three out of 60 from four separate preparations of fura-2loaded cells) exhibited responses typical of GI neurons $[9,14,34]$. Addition of the AMPK activator AICAR (400 $\mu \mathrm{mol} / \mathrm{l}$; [27]) at $15 \mathrm{mmol} / \mathrm{l}$ glucose activated all of these GI neurons $(n=12 / 12$ cells from 11 separate preparations; Fig. 1a,b). In contrast, $8 \%$ of neurons (five out of 60 cells from four separate preparations of fura-2-loaded cells) were identified as GE neurons $[9,11,14,34]$, and in none of these cells was the response to glucose affected by AICAR (Fig. 1c,d). Similarly, AICAR exerted no effect on non-glucose-responsive neurons (Fig. 1e,f).

In order to further explore the possible role of AMPK in mediating the effects of low glucose concentrations on GI neurons, we investigated directly the cells' electrical responses to changes in glucose concentration or forced changes in AMPK activity. Immediately prior to performing amphotericin perforated patch-clamp recordings, potentially glucose-responsive neurons were identified as those having

C

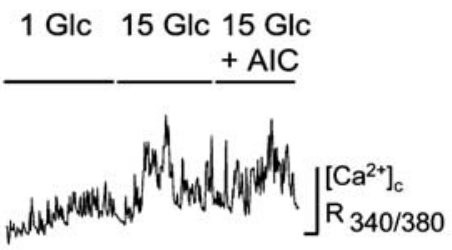

e

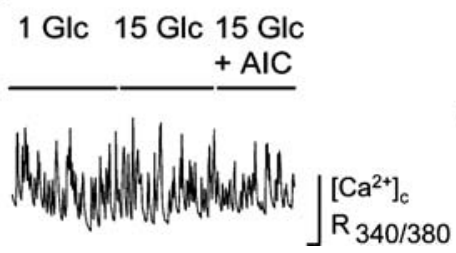

Fig. 1 Glucose- and AICAR-induced changes in $\left[\mathrm{Ca}^{2+}\right]_{\mathrm{c}}$ measured in hypothalamic neurons with fluo-3 (a) or fura-2 (c, e). AICAR (AIC, $400 \mu \mathrm{mol} / \mathrm{l}$ ) was applied as shown. Typical response to AICAR observed in (a) a GI, (c) a GE and (e) a non-GR neuron. Glc, glucose. b, d, f Mean normalised AUC for GI $(n=9)$, GE $(n=5)$ and non-GR neurons $(n=3)$, respectively. Vertical bar: (a) $100 F_{488}$ units, (c, e) 0.1 Ratio $_{340 / 380}$ units. Horizontal bars (a, c, e), 2 min. Open bars: (b) $0 \mathrm{mmol} / 1$ glucose, (d, f) $1.0 \mathrm{mmol} / \mathrm{l}$ glucose. Grey and black bars, $15 \mathrm{mmol} / \mathrm{l}$ glucose and $15 \mathrm{mmol} / \mathrm{l}$ glucose plus AICAR respectively. Error bars, SEM for each condition. ${ }^{* *} p<0.01$

$>20 \%$ higher basal $\mathrm{Ca}^{2+}$ levels than the population mean as assessed by fluo-3 fluorescence.

Addition of AICAR ( $400 \mu \mathrm{mol} / \mathrm{l})$ was sufficient to activate GI neurons at elevated $(15 \mathrm{mmol} / \mathrm{l})$ glucose (response to AICAR: $n=4 / 4$ GI neurons from four separate preparations; Fig. 2a,b). In contrast, the electrical activity of GE neurons was unaffected by AICAR ( $n=3 / 3$ GE neurons from three separate preparations; Fig. 2c,d), consistent with the failure of this agent to affect $\mathrm{Ca}^{2+}$ oscillations in these cells (see above).

Application of the selective AMPK inhibitor Compound $\mathrm{C}[35,36]$ at $1.0 \mathrm{mmol} / \mathrm{l}$ glucose suppressed the activity of GI neurons $(n=5 / 5$ GI neurons from four separate preparations; Fig. 3a,b). In contrast, addition of Compound $\mathrm{C}$ had no consistent effects on the activity of GE or other neuronal subtypes (data not shown).

Leptin suppresses the activation of hypothalamic GI neurons by low glucose concentrations: reversal by 
Fig. 2 Impact of glucose and AICAR on the electrical activity of hypothalamic neurons during current clamp. a Response to $\operatorname{AICAR}(A I C ; 400 \mu \mathrm{mol} / \mathrm{l})$ of a GI neuron. b Mean normalised action potential $(A P)$ frequencies of GI neurons $(n=4)$. Observed frequencies at $1.0 \mathrm{mmol} / \mathrm{l}$ glucose (Glc) varied from 11 to 149 APs/min. $\mathbf{c}$ Effects of AICAR on a GE neuron. d Mean normalised action potential frequency of $\mathrm{GE}$ neurons $(n=3)$. Observed frequencies at $1.0 \mathrm{mmol} / \mathrm{l}$ glucose were 7 to $16 \mathrm{APs} / \mathrm{min}$. Vertical bar (a, c), $30 \mathrm{mV}$; horizontal bar, 2 min. Open, grey and black bars (b, d) represent $1.0 \mathrm{mmol} / \mathrm{glu}$ cose, $15 \mathrm{mmol} / \mathrm{l}$ glucose, and $15 \mathrm{mmol} / 1$ glucose plus AICAR respectively. Error bars show SEM for each condition. $* p<0.05$
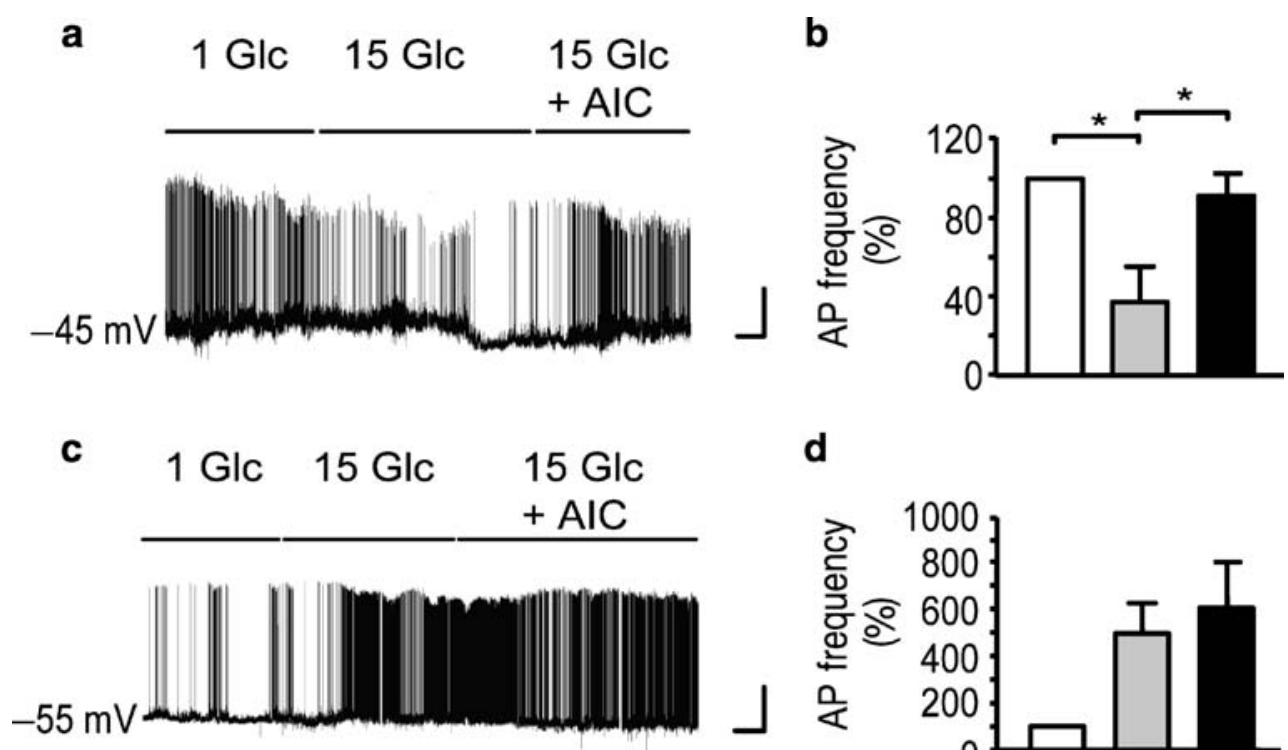

d

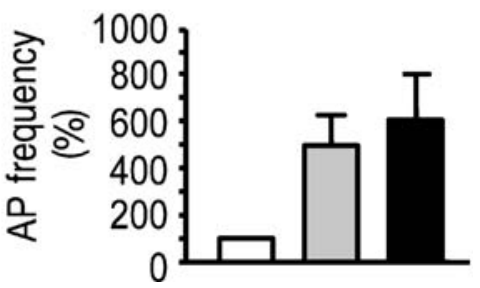

AICAR We next determined the possible involvement of changes in AMPK activity in the responses of GI neurons to leptin. In this set of experiments, approximately $4 \%$ of

a
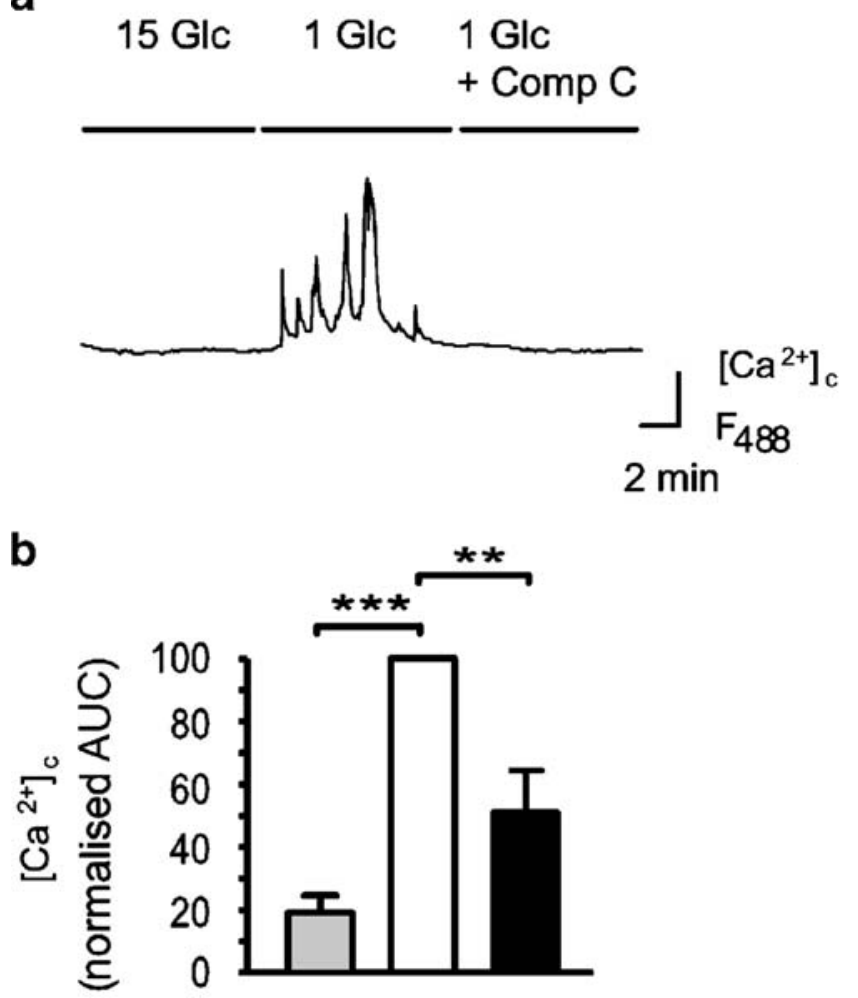

Fig. 3 Effects of inhibition of AMPK activity in hypothalamic GI neurons measured by imaging $\left[\mathrm{Ca}^{2+}\right]_{\mathrm{c}}$ with fluo-3. a Effects of Compound C $(15 \mu \mathrm{mol} / \mathrm{l})$ on a GI neuron. b Mean normalised AUC $(n=5)$. Vertical bars (a), $50 F_{488}$ units; horizontal bar, 2 min. Open, grey and black bars (b) represent $1.0 \mathrm{mmol} / \mathrm{l}$ glucose, $15 \mathrm{mmol} /$ 1 glucose, and $1.0 \mathrm{mmol} / \mathrm{l}$ glucose plus Compound C respectively. Error bars show SEM for each condition. ${ }^{* *} p<0.01, * * * p<0.001$ cells (nine of 208 tested from eight separate preparations of fluo-3 loaded cells) were identified as GI neurons.

Examined at $1.0 \mathrm{mmol} / \mathrm{l}$ glucose, leptin $(10 \mathrm{nmol} / \mathrm{l} ;$ [12]) caused a dramatic and rapid decrease in the frequency and amplitude of $\left[\mathrm{Ca}^{2+}\right]_{\mathrm{c}}$ oscillations in the majority of GI neurons sampled ( $n=7 / 9$ GI neurons from eight preparations; Fig. 4a). One GI cell displayed no detectable change in $\left[\mathrm{Ca}^{2+}\right]_{\mathrm{c}}$ in response to leptin, and in one further cell $\left[\mathrm{Ca}^{2+}\right]_{\mathrm{c}}$ was increased; the latter was excluded from the analysis shown in Fig. 4b. Inhibition by leptin was reversed by AICAR in the majority of GI neurons $(n=4 / 5$ GI neurons from seven preparations; Fig. 4c,d). Consistent with previous reports [12, 37, 38], leptin exerted mixed effects on the activity of GE neurons. The effects of AMPK manipulation on leptin-induced $\mathrm{Ca}^{2+}$ responses were not, therefore, examined further in GE cells.

Glucose-induced changes in $\left[\mathrm{Ca}^{2+}\right]_{c}$ in NPY neurons Previous reports using post-fixation immunocytochemistry have indicated that some, but not all, arcuate nucleus GI neurons produce NPY $[33,39,40]$. In the present studies, only $\sim 3 \%$ of neurons ( 11 of 350 cells) stained positively for NPY, while $~ 5 \%$ of neurons ( 33 of 710 cells) were glucoseinhibited, comparable to recent measurements by others using similar culture conditions [41]. Thus, a maximum of $60 \%$ of GI neurons in these cultures were likely to be NPYpositive. To explore therefore the involvement of AMPK in glucose-sensing in NPY and agouti-related peptide neurons, we constructed a recombinant adenovirus producing the GFP-based fluorescent $\mathrm{Ca}^{2+}$ indicator protein ratiometricpericam [22] under the control of the NPY promoter. As expected, neurons producing the NPY-promoter-driven ratiometric-pericam were also positive for NPY immunore- 
Fig. 4 Effects of leptin on the activity of hypothalamic GI neurons measured by imaging $\left[\mathrm{Ca}^{2+}\right]_{\mathrm{c}}$ with fluo-3: reversal by AICAR Leptin (lep; $10 \mathrm{nmol} / \mathrm{l})$, or AICAR $(A I C ; 400 \mu \mathrm{mol} / \mathrm{l})$ were applied as shown. a Response of a typical GI neuron to leptin. b Mean normalised changes in AUC ( $n=8$ cells). $G l c$, glucose. c Effect of AICAR on the inhibition of a GI neuron by leptin. d Mean normalised $\operatorname{AUC}(n=5)$. Vertical bars $(\mathbf{a}, \mathbf{c})$, $50 F_{488}$ units; horizontal bars (a, c), 2 min. Open, grey and black bars $(\mathbf{b}, \mathbf{d})$ represent $1.0 \mathrm{mmol} / 1$ glucose, $15 \mathrm{mmol} / \mathrm{l}$ glucose, and $1.0 \mathrm{mmol} / \mathrm{l}$ glucose plus leptin respectively. Dark grey bar (d), $1.0 \mathrm{mmol} / 1$ glucose plus leptin plus AICAR. Error bars show SEM for each condition. ${ }^{*} p<0.05$ a
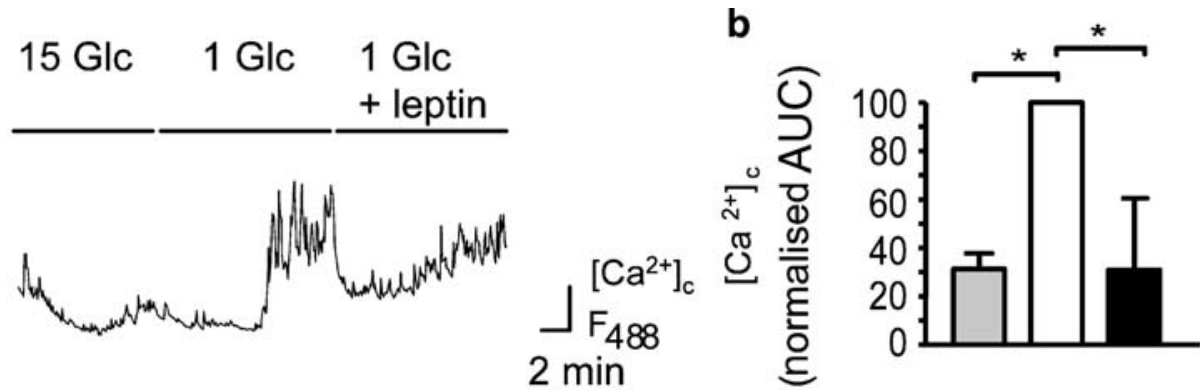

C
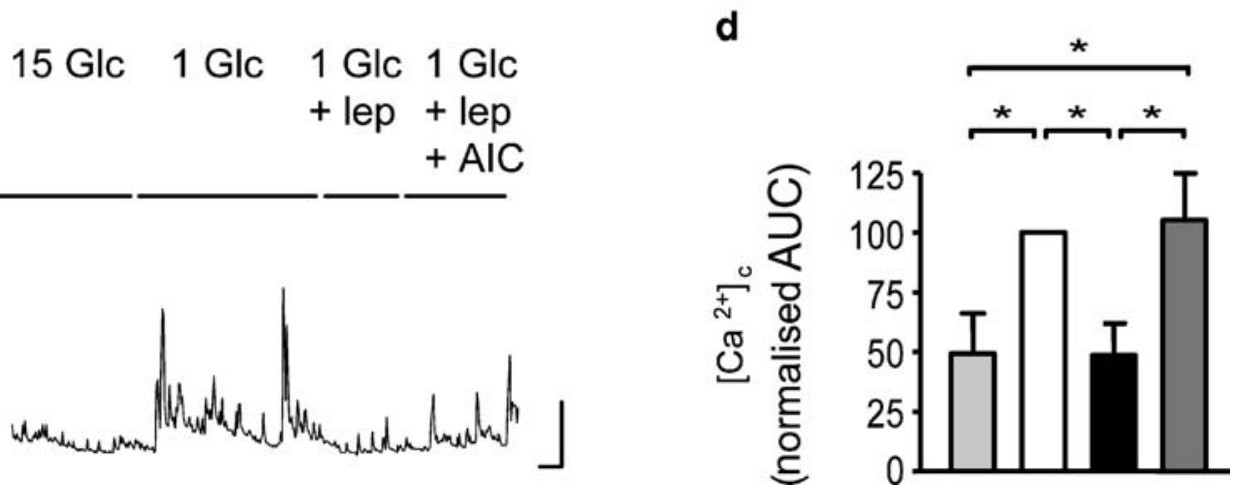

activity ( $n=7 / 7$ cells; Fig. 5a,b), but negative for POMC immunoreactivity (Fig. 5b).

Glucose deprivation (1.0 vs $15 \mathrm{mmol} / \mathrm{l}$ glucose) increased apparent $\left[\mathrm{Ca}^{2+}\right]_{\mathrm{c}}$ in $80 \%$ of $\mathrm{Npy}$-expressing neurons ( $n=4 / 5 \mathrm{Npy}$-expressing neurons from four separate preparations; Fig. 5c,d). Indicating that the effects of glucose were likely to involve changes in AMPK activity, the presence of Compound $\mathrm{C}(15 \mu \mathrm{mol} / \mathrm{l})$ for the duration of these experiments prevented the subsequent activation of these Npy neurons by low $(1.0 \mathrm{mmol} / \mathrm{l})$ glucose concentrations $(n=3 / 3$ neurons; Fig. 5e,f). Similarly, pre-treatment of cells with AICAR $(400 \mu \mathrm{mol} / \mathrm{l})$ also prevented a further activation of Npy neurons by low glucose concentrations ( $n=3 / 3$ neurons; Fig. $5 \mathrm{~g}, \mathrm{~h}$ ). We would note that the peak of the response to AICAR is likely to be observed during the pre-incubation period in these experiments, such that $\mathrm{Ca}^{2+}$ levels had dropped to close to basal before recordings (Fig. 5g,h). Nevertheless, it seems likely that the persistent activation of AMPK in the AICAR-treated cells explains the absence of a subsequent $\mathrm{Ca}^{2+}$ response upon shifting to $1.0 \mathrm{mmol} / \mathrm{l}$ glucose.

\section{Discussion}

Although reported direct measurements of glucose in the ventromedial hypothalamus have ranged between 0.5 and $2.5 \mathrm{mmol} / 1[29,30]$, the glucose concentrations to which glucose-sensing neurons are exposed remain controversial.
Importantly, the position of glucose-sensing neurons in the arcuate and ventromedial nuclei of the hypothalamus means that they and their projections may be in close association with the median eminence, where the blood-brain barrier is necessarily 'leaky' to allow the release of hypothalamic hormones and the action of circulating peptides [42], and where glucose concentrations may therefore approach blood levels. Although in this study we used concentrations of glucose that may lie outside the physiological range of brain glucose concentrations, within these constraints we nonetheless provide data that implicate changes in AMPK activity in glucose sensing by GI neurons, as discussed below.

Recent work in whole animals has demonstrated a likely role for AMPK in the regulation by glucose and leptin of hypothalamic neurons, and hence feeding behaviour [20, 21, 43-45], at least in the long term (days/weeks). These earlier studies demonstrated changes in AMPK activity and phosphorylation state in the basomedial hypothalamus in response to intracerebroventricular introduction of glucose or leptin, and showed reciprocal effects of AMPK activation or inhibition on feeding behaviour. Importantly, however, the sub-types of neurons in which changes in AMPK activity may be important were not fully defined, nor was it established whether AMPK may influence the acute responses (membrane de/hyper polarisation, $\mathrm{Ca}^{2+}$ oscillations) to satiety factors of the implicated cells. The principal aim of the present work was to address these two issues.

To this end, we used cultures of hypothalamic neurons in which GI and GE neurons are retained, albeit at somewhat reduced numbers $(\sim 5 \%$ and $7 \%$ of total for GI 


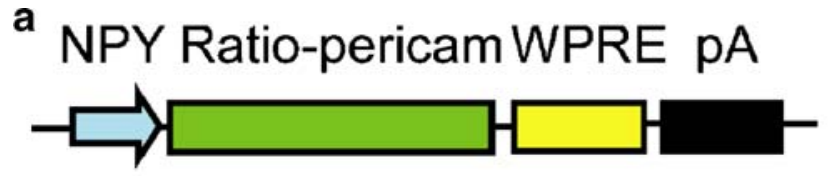

b
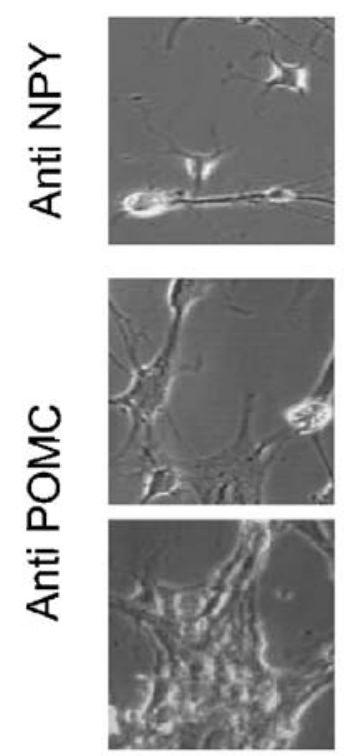

C

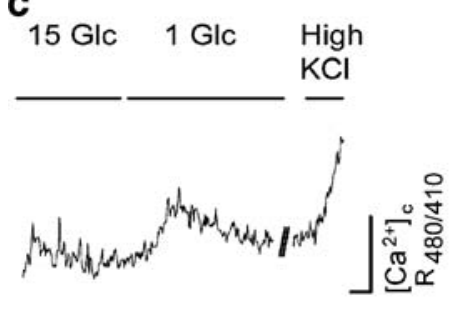

e

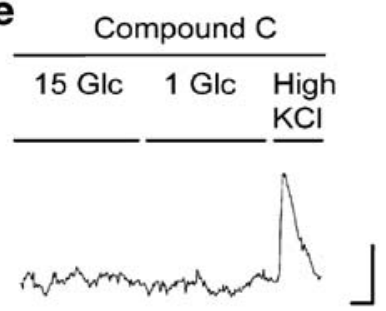

g

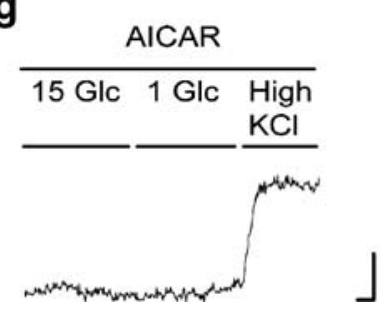

Pericam
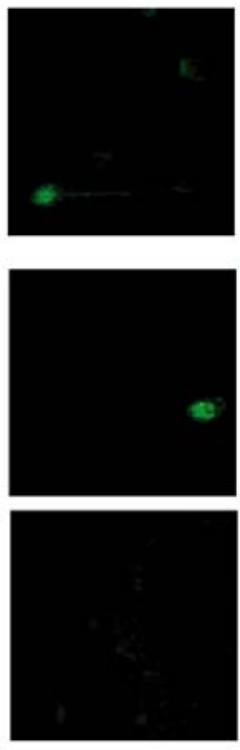

d

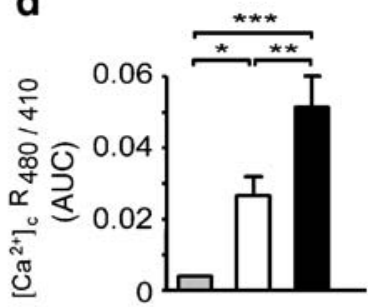

f

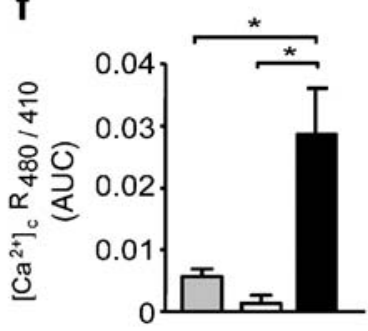

h

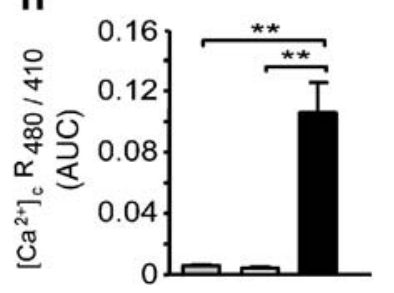

and GE neurons, respectively) compared with freshly isolated slice preparations (reported to be $\sim 3-20 \%$ for GI, and $\sim 20 \%$ for GE) $[13-15,17,41]$. This variation in the published values probably reflects in part the size of the
Fig. 5 Effects of glucose and AICAR on $\left[\mathrm{Ca}^{2+}\right]_{\mathrm{c}}$ changes in hypothalamic NPY-expressing neurons imaged with a recombinant targeted ratiometric-pericam. a, b NPY immunoreactivity in NPYratiometric-pericam-expressing hypothalamic neurons was assessed as described. c Response to glucose $(G l c)$ deprivation of an NPYratiometric-pericam-producing neuron, with (d) mean AUC $(n=4$ GI neurons). e, f Effect of Compound $\mathrm{C}(15 \mu \mathrm{mol} / \mathrm{l})$ on the glucose responses of NPY neurons $(n=3)$. $\mathbf{g}, \mathbf{h}$ Effect of AICAR (AIC) pretreatment $(15 \mathrm{~min})$ on subsequent glucose responses of NPY neurons $(n=3)$. Vertical bars $(\mathbf{c}, \mathbf{e}, \mathbf{g})$ show 0.05 Ratio480/410 units; horizontal bars (c, e, g), $2 \mathrm{~min}$. Scale bar (b), $10 \mu \mathrm{m}$. Open, grey and black bars represent: (d) $1.0 \mathrm{mmol} / 1$ glucose, $15 \mathrm{mmol} / 1$ glucose, and high (40 mmol/1) KCl respectively; (f) $1.0 \mathrm{mmol} / 1$ glucose plus Compound C, $15 \mathrm{mmol} / \mathrm{l}$ glucose plus Compound $\mathrm{C}$, and high $(40 \mathrm{mmol} / \mathrm{l}) \mathrm{KCl}$ plus Compound $\mathrm{C}$ respectively; (h) $1.0 \mathrm{mmol} / 1$ glucose plus AICAR, $15 \mathrm{mmol} / 1$ glucose plus AICAR, and high $(40 \mathrm{mmol} / \mathrm{l}) \mathrm{KCl}$ plus AICAR respectively. Error bars show SEM for each condition. ${ }^{*} p<0.05,{ }^{* *} p<0.01, * * * p<0.001$

hypothalamic region taken for cell isolation. In the present study, the region taken included both the ventromedial and arcuate nuclei, but the presence of some neurons from neighbouring nuclei cannot be excluded. As such, the proportion of glucose-regulated cells is expected to be somewhat lower than some of the above published values, where one of the nuclei was investigated selectively. Moreover, an ex vivo cell culture preparation whose characteristics have in large part previously been defined [17] was adopted here to permit the introduction of a targeted recombinant $\mathrm{Ca}^{2+}$ probe into a selected neuronal sub-population by adenoviral gene delivery. We would stress, however, that changes in the glucose-sensing mechanisms of these cells [41], as well as cell-cell interactions and interactions with neighbouring astrocytes [17], may well occur upon isolation and culture, thereby affecting the observed responses.

For each of the questions posed, individual groups of experiments were performed on at least three (electrophysiology) or four to eleven $\left(\mathrm{Ca}^{2+}\right.$ imaging) independent isolations, each involving twelve separate cultures of neurons. In this way, we were able to obtain sufficient data from a relatively limited supply of glucose-regulated cells in the basomedial hypothalamus to perform statistically validated comparisons. Preliminary experiments (see Electronic supplementary material [ESM] Fig. 1) suggested that opening of $\mathrm{K}_{\mathrm{ATP}}$ channels could be involved in the activation of only a minority of GI neurons by low glucose concentrations (for a more detailed explanation of these studies see ESM, Results section). By contrast, we demonstrated in the main study that changes in AMPK activity are likely to mediate $\mathrm{K}_{\mathrm{ATP}}$ channel-independent effects of glucose on GI, but not on GE neurons. Although in the present studies we were unable to readily monitor changes in AMPK activity or $\alpha$-subunit phosphorylation at the regulatory site $\left(\mathrm{Thr}^{172}\right)$ at the single cell level (unpublished data, P. D. Mountjoy, G. A. Rutter), the cell permeant AMPK activator AICAR mimicked the effects of 

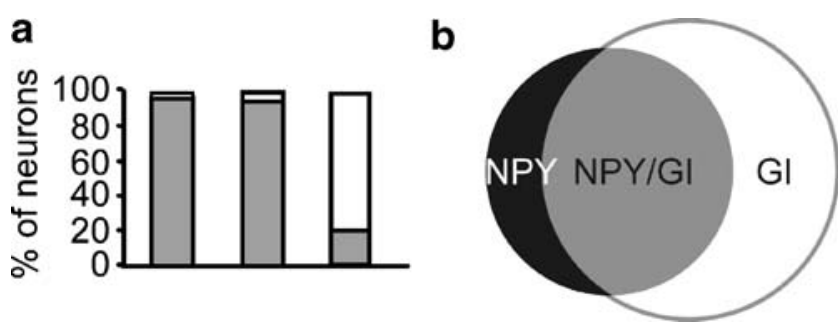

Fig. 6 Proportions of $N p y$-expressing, GI, and $N p y$-expressing GI neurons in hypothalamic neuronal cultures. Proportions of Npyexpressing neurons were determined by immunocytochemistry, proportions of GI neurons were determined by $\left[\mathrm{Ca}^{2+}\right]_{\mathrm{c}}$ imaging with fluo-3 or fura-2, and proportions of $N p y$-expressing GI neurons were determined using the NPY-ratiometric-pericam adenovirus described in Fig. 5. a White regions represent NPY positive, GI, or NPYpericam producing GI neurons respectively in the first, second and third bars (from the left). Grey regions represent NPY negative, nonGI, and NPY-pericam producing non-GI neurons respectively in the first, second, and third bars (from the left). Dark, grey and white shading (b): NPY, NPY/GI and GI respectively

low glucose on GI neurons. This effect was probably mediated by activation of AMPK, given that the alternative effects of AICAR (e.g. increasing extracellular adenosine and consequent activation of adenosine receptors) [46] appear unlikely to be involved in neurons in this region of the hypothalamus [47]. Conversely, suppression of AMPK activity with the selective AMPK inhibitor Compound C reversed the effects of low glucose on GI neurons. Hence, two pharmacological agents expected to exert opposing effects on AMPK activity also caused opposing changes in the activity of GI neurons, implicating this enzyme as the common target.

We would emphasise that genetic manipulation of neuronal AMPK activity with currently available adenoviruses [27] expressing active or dominant-negative AMPK under the cytomegalovirus promoter was not feasible in the current study. Infection with these viruses led to only weak expression in neurons (data not shown). By contrast, use of a single cell-type-specific promoter (e.g. NPY) to drive
AMPK production was not considered a viable approach given the apparent cellular heterogeneity of the GI neuron population (see below).

By developing a molecularly targeted probe (NPYratiometric-pericam), we show that the majority of $\mathrm{Npy}$ expressing neurons are likely to be GI in nature, and to be regulated by glucose and leptin through changes in AMPK activity. Since $80 \%$ of $N p y$-expressing neurons were inhibited by elevated glucose concentrations (Fig. 6a), and since $3 \%$ of neurons in culture were NPY-positive, approximately $2 \%$ of basomedial hypothalamic neurons are likely to be $N p y$-expressing and GI in nature. Given that $\sim 5 \%$ of neurons in culture are GI, $\sim 40 \%$ of the GI neurons in the basomedial hypothalamus are likely to express $N p y$ (assuming a decrease of glucose sensitivity upon cell culture) [41] (Fig. 6b). Although the present study identified AMPK as being involved in glucose-sensing by Npy-expressing GI neurons in cultured hypothalamic neurons, these findings also raise the possibility that $N p y$ expressing GI neurons could play a role in the recently identified effects of AMPK activation or inhibition on satiety and feeding in vivo [20,21].

Accordingly, intracerebroventricular injection of adenovirus encoding activated or inactive (dominant-negative) forms of AMPK [20] has previously been shown to affect NPY production in the hypothalamus. It remains to be explored whether the control of these two processes, i.e. electrical activity and Npy gene expression, are linked, although the present data would be consistent with mechanisms whereby changes in nuclear $\left[\mathrm{Ca}^{2+}\right][48]$ or secretion of NPY, followed by an autocrine action of the hormone, led to alterations in Npy expression. Interestingly, the involvement of the transcriptional co-activator CREB-regulated transcription coactivator 2 (also known as TORC2), a known target of AMPK [49], in the control of Npy expression appears unlikely, given that AMPK activation at low glucose is expected to cause nuclear exclusion of this factor.
Fig. 7 Potential mechanism for involvement of AMPK in glucose and leptin signalling by hypothalamic $N p y$-expressing GI neurons. See text for details

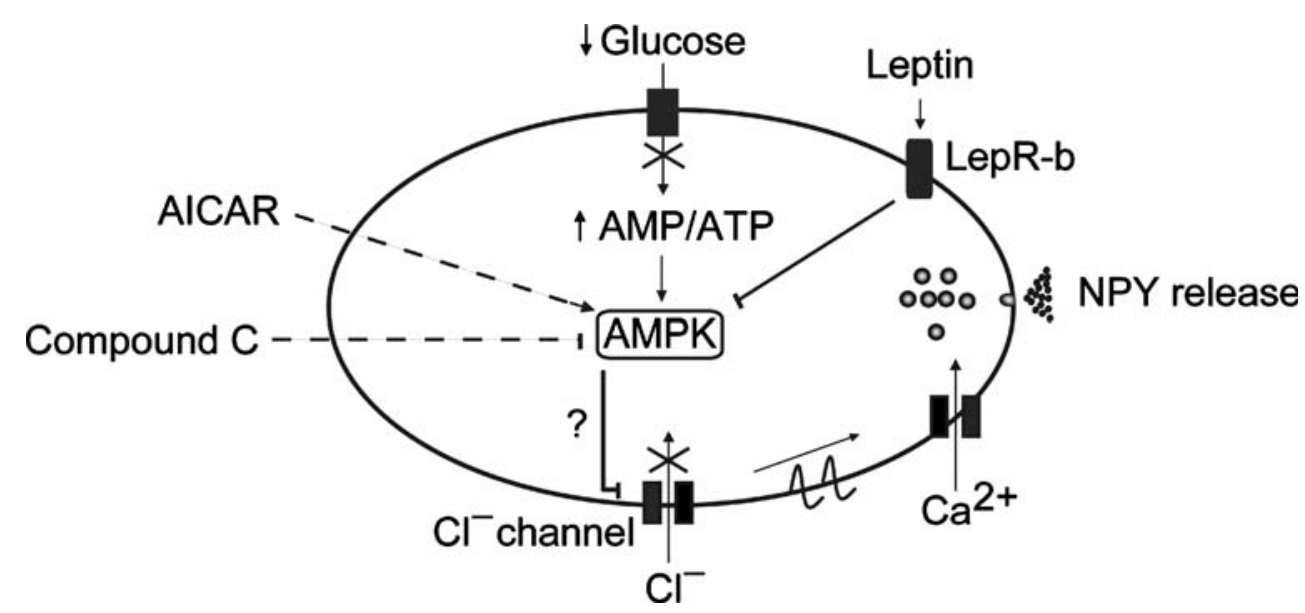


It has previously been suggested that suppression of AMPK activity is required for the anorexigenic effects of leptin [20]. In the present study, activation of AMPK was shown to reverse the leptin-induced inhibition of GI neurons in the majority $(4 / 5,80 \%)$ of GI neurons examined. These results potentially indicate that leptin exerts its inhibitory effects through the suppression of AMPK activity, and subsequent plasma membrane hyperpolarisation in GI (including NPY-positive) neurons. However, further studies are required to determine whether such a mechanism operates physiologically.

Based on the data presented here, we propose that AMPK may be involved in the activation of GI neurons at low glucose concentrations via one or more of the following mechanisms (Fig. 7). As glucose concentrations fall, the rate of sugar uptake through solute carrier family 2 (facilitated glucose transporter), member 3 (also known as GLUT3) [15] and metabolism via glucokinase and the glycolytic pathway [14] will fall. The resultant increase in the AMP : ATP ratio is then expected to activate AMPK [18]. By contrast, leptin's actions are probably mediated by its binding to the leptin receptor $\mathrm{b}$ isoform [15]. However, whether this leads to changes in the AMP : ATP ratio is unclear.

By what means may changes in AMPK activity affect action potential firing and $\mathrm{Ca}^{2+}$ oscillations? One potential mechanism is the inactivation of plasma membrane $\mathrm{Cl}^{-}$ channels [13], possibly via phosphorylation of these channels by plasma membrane-associated AMPK $\alpha 2$ (see ESM, immunocytochemical results; ESM Fig. 2). Alternative mechanisms include the phosphorylation by AMPK of well-defined metabolic enzyme targets such as acetyl-CoA carboxylase [18]. The resultant decreases in intracellular malonyl-CoA levels and increases in long chain acyl-CoA disposal by $\beta$-oxidation may then lead to changes in ion channel, and consequently electrical activity. Long-chain acyl-CoAs have previously been shown to activate $\mathrm{K}_{\mathrm{ATP}}$ channels in pancreatic beta cells [50], and to have direct effects on the ryanodine-sensitive $\mathrm{Ca}^{2+}$ release channel [51]. Consequently, potential actions of long-chain acylCoAs on the aforementioned $\mathrm{Cl}^{-}$channel proposed to be involved in glucose-sensing by GI neurons [13] seem to be conceivable. In support of the latter hypothesis, fatty acid synthase inhibitors have been shown to cause weight loss in rodents by increasing hypothalamic malonyl-CoA levels [52]. Irrespective of the mechanisms involved, enhanced release of the orexigenic peptide NPY could act via a series of 'second-order' neurons to regulate cerebral cortex and autonomic preganglionic neurons involved in controlling feeding behaviour [3], and possibly affect counter-regulatory responses to regulate blood glucose levels [44].

Acknowledgements We thank M. J. Ashford and S. Mirshamsi (University of Dundee, Scotland) for help in the establishment of neuronal cultures, and N. Balthasar for discussion. This work was supported by grants to G. A. Rutter from the Wellcome Trust (Project 062321; Programme 067081/Z/02/Z), and by a Wellcome Trust Prize Studentship to P. D. Mountjoy. G. A. Rutter is a Wellcome Trust Research Leave Fellow.

\section{References}

1. Marx J (2003) Cellular warriors at the battle of the bulge. Science 299:846-849

2. Grundy SM, Hansen B, Smith SC Jr et al (2004) Clinical management of metabolic syndrome: report of the American Heart Association/National Heart, Lung, and Blood Institute/ American Diabetes Association conference on scientific issues related to management. Circulation 109:551-556

3. Elias CF, Aschkenasi C, Lee C et al (1999) Leptin differentially regulates NPY and POMC neurons projecting to the lateral hypothalamic area. Neuron 23:775-786

4. Wang Q, Bing C, Al-Barazanji K et al (1997) Interactions between leptin and hypothalamic neuropeptide $\mathrm{Y}$ neurons in the control of food intake and energy homeostasis in the rat. Diabetes 46:335-341

5. Jobst EE, Enriori PJ, Cowley MA (2004) The electrophysiology of feeding circuits. Trends Endocrinol Metab 15:488-499

6. Cowley MA, Smart JL, Rubinstein M et al (2001) Leptin activates anorexigenic POMC neurons through a neural network in the arcuate nucleus. Nature 411:480-484

7. Cowley MA, Smith RG, Diano S et al (2003) The distribution and mechanism of action of ghrelin in the CNS demonstrates a novel hypothalamic circuit regulating energy homeostasis. Neuron 37:649-661

8. Shintani M, Ogawa Y, Ebihara K et al (2001) Ghrelin, an endogenous growth hormone secretagogue, is a novel orexigenic peptide that antagonizes leptin action through the activation of hypothalamic neuropeptide $\mathrm{Y} / \mathrm{Y} 1$ receptor pathway. Diabetes 50:227-232

9. Oomura Y, Ono T, Ooyama H, Wayner MJ (1969) Glucose and osmosensitive neurones of the rat hypothalamus. Nature 222:282-284

10. Oomura Y, Ooyama H, Sugimori M, Nakamura T, Yamada Y (1974) Glucose inhibition of the glucose-sensitive neurone in the rat lateral hypothalamus. Nature 247:284-286

11. Ashford ML, Boden PR, Treherne JM (1990) Glucose-induced excitation of hypothalamic neurones is mediated by ATP-sensitive $\mathrm{K}^{+}$channels. Pflugers Arch 415:479-483

12. Spanswick D, Smith MA, Groppi VE, Logan SD, Ashford ML (1997) Leptin inhibits hypothalamic neurons by activation of ATP-sensitive potassium channels. Nature 390:521-525

13. Song Z, Levin BE, McArdle JJ, Bakhos N, Routh VH (2001) Convergence of pre- and postsynaptic influences on glucosensing neurons in the ventromedial hypothalamic nucleus. Diabetes 50:2673-2681

14. Dunn-Meynell AA, Routh VH, Kang L, Gaspers L, Levin BE (2002) Glucokinase is the likely mediator of glucosensing in both glucose-excited and glucose-inhibited central neurons. Diabetes 51:2056-2065

15. Kang L, Routh VH, Kuzhikandathil EV, Gaspers LD, Levin BE (2004) Physiological and molecular characteristics of rat hypothalamic ventromedial nucleus glucosensing neurons. Diabetes 53:549-559

16. Rutter GA (2004) Visualising insulin secretion. The Minkowski Lecture 2004. Diabetologia 47:1861-1872

17. Ainscow EK, Mirshamsi S, Tang T, Ashford ML, Rutter GA (2002) Dynamic imaging of free cytosolic ATP concentration during fuel sensing by rat hypothalamic neurones: evidence for ATP-independent control of ATP-sensitive $\mathrm{K}(+)$ channels. J Physiol 544:429-445 
18. Hardie DG, Carling D, Carlson M (1998) The AMP-activated/ SNF1 protein kinase subfamily: metabolic sensors of the eukaryotic cell? Annu Rev Biochem 67:821-855

19. Rutter GA, da Silva Xavier G, Leclerc I (2003) Roles of 5'AMP-activated protein kinase (AMPK) in mammalian glucose homoeostasis. Biochem J 375:1-16

20. Minokoshi Y, Alquier T, Furukawa N et al (2004) AMP-kinase regulates food intake by responding to hormonal and nutrient signals in the hypothalamus. Nature 428:569-574

21. Andersson U, Filipsson K, Abbott CR et al (2004) AMP-activated protein kinase plays a role in the control of food intake. J Biol Chem 279:12005-12008

22. Nagai T, Sawano A, Park ES, Miyawaki A (2001) Circularly permuted green fluorescent proteins engineered to sense $\mathrm{Ca}^{2+}$. Proc Natl Acad Sci USA 98:3197-3202

23. Glover CPJ, Bienemann AS, Heywood DJ, Cosgrave AS, Uney JB (2002) Adenoviral-mediated, high-level, cell-specific transgene expression: a SYN1-WPRE cassette mediates increased transgene expression with no loss of neuron specificity. Mol Ther 5:509-516

24. He TC, Zhou S, da Costa LT, Yu J, Kinzler KW, Vogelstein B (1998) A simplified system for generating recombinant adenoviruses. Proc Natl Acad Sci USA 95:2509-2514

25. Williams AG, Hargreaves AC, Gunn-Moore FJ, Tavare JM (1998) Stimulation of neuropeptide Y gene expression by brainderived neurotrophic factor requires both the phospholipase Cgamma and Shc binding sites on its receptor, TrkB. Biochem J 333:505-509

26. Ainscow EK, Rutter GA (2001) Mitochondrial priming modifies $\mathrm{Ca}^{2+}$ oscillations and insulin secretion in pancreatic islets. Biochem J 353:175-180

27. da Silva Xavier G, Leclerc I, Varadi A, Tsuboi T, Moule SK, Rutter GA (2003) Role for AMP-activated protein kinase in glucose-stimulated insulin secretion and preproinsulin gene expression. Biochem J 371:761-774

28. Varadi A, Rutter GA (2002) Dynamic imaging of endoplasmic reticulum $\mathrm{Ca}^{2+}$ concentration in insulin-secreting MIN6 cells using recombinant targeted cameleons: roles of sarco(endo) plasmic reticulum $\mathrm{Ca}^{2+}$-ATPase (SERCA)-2 and ryanodine receptors. Diabetes 51:S190-S201

29. Silver I, Erecinska M (1994) Extracellular glucose concentration in mammalian brain: continuous monitoring of changes during increased neuronal activity and upon limitation in oxygen supply in normo-, hypo-, and hyperglycemic animals. J Neurosci 14:5068-5076

30. de Vries MG, Arseneau LM, Lawson ME, Beverly JL (2003) Extracellular glucose in rat ventromedial hypothalamus during acute and recurrent hypoglycemia. Diabetes 52:2767-2773

31. Fioramonti X, Lorsignol A, Taupignon A, Penicaud L (2004) A new ATP-sensitive $\mathrm{K}+$ channel-independent mechanism is involved in glucose-excited neurons of mouse arcuate nucleus. Diabetes 53:2767-2775

32. Mobbs CV, Kow LM, Yang XJ (2001) Brain glucose-sensing mechanisms: ubiquitous silencing by aglycemia vs. hypothalamic neuroendocrine responses. Am J Physiol Endocrinol Metab 281: E649-E654

33. Muroya S, Yada T, Shioda S, Takigawa M (1999) Glucosesensitive neurons in the rat arcuate nucleus contain neuropeptide $\mathrm{Y}$. Neurosci Lett 264:113-116

34. Levin BE, Dunn-Meynell AA, Routh VH (1999) Brain glucose sensing and body energy homeostasis: role in obesity and diabetes. Am J Physiol 276:R1223-R1231
35. Zhou G, Myers R, Li Y et al (2001) Role of AMP-activated protein kinase in mechanism of metformin action. J Clin Invest 108: $1167-1174$

36. Kim EK, Miller I, Aja S et al (2004) C75, a fatty acid synthase inhibitor, reduces food intake via hypothalamic AMP-activated protein kinase. J Biol Chem 279:19970-19976

37. Muroya S, Funahashi H, Yamanaka A et al (2004) Orexins (hypocretins) directly interact with neuropeptide Y, POMC and glucose-responsive neurons to regulate $\mathrm{Ca}^{2+}$ signaling in a reciprocal manner to leptin: orexigenic neuronal pathways in the mediobasal hypothalamus. Eur J Neurosci 19:1524-1534

38. Wang R, Liu X, Hentges ST et al (2004) The regulation of glucose-excited neurons in the hypothalamic arcuate nucleus by glucose and feeding-relevant peptides. Diabetes 53:1959-1965

39. Muroya S, Uramura K, Sakurai T, Takigawa M, Yada T (2001) Lowering glucose concentrations increases cytosolic $\mathrm{Ca}^{2+}$ in orexin neurons of the rat lateral hypothalamus. Neurosci Lett 309:165-168

40. Burdakov D, Gerasimenko O, Verkhratsky A (2005) Physiological changes in glucose differentially modulate the excitability of hypothalamic melanin-concentrating hormone and orexin neurons in situ. J Neurosci 25:2429-2433

41. Kang L, Dunn-Meynell AA, Routh VH et al (2006) Glucokinase is a critical regulator of ventromedial hypothalamic neuronal glucosensing. Diabetes 55:412-420

42. Ganong WF (2000) Circumventricular organs: definition and role in the regulation of endocrine and autonomic function. Clin Exp Pharmacol Physiol 27:422-427

43. Kim M-S, Park J-Y, Namkoong C et al (2004) Anti-obesity effects of [alpha]-lipoic acid mediated by suppression of hypothalamic AMP-activated protein kinase. Nat Med 10:727-733

44. McCrimmon RJ, Fan X, Ding Y, Zhu W, Jacob RJ, Sherwin RS (2004) Potential role for AMP-activated protein kinase in hypoglycemia sensing in the ventromedial hypothalamus. Diabetes 53:1953-1958

45. Namkoong C, Kim MS, Jang PG et al (2005) Enhanced hypothalamic AMP-activated protein kinase activity contributes to hyperphagia in diabetic rats. Diabetes 54:63-68

46. Gadalla AE, Pearson T, Currie AJ et al (2004) AICA riboside both activates AMP-activated protein kinase and competes with adenosine for the nucleoside transporter in the CA1 region of the rat hippocampus. J Neurochem 88:1272-1282

47. Chen ZP, Levy A, Lightman SL (1994) Activation of specific ATP receptors induces a rapid increase in intracellular calcium ions in rat hypothalamic neurons. Brain Res 641:249-256

48. Hardingham GE, Chawla S, Johnson CM, Bading H (1997) Distinct functions of nuclear and cytoplasmic calcium in the control of gene expression. Nature 385:260-265

49. Koo S-H, Flechner L, Qi L et al (2005) The CREB coactivator TORC2 is a key regulator of fasting glucose metabolism. Nature 437:1109-1111

50. Gribble FM, Proks P, Corkey BE, Ashcroft FM (1998) Mechanism of cloned ATP-sensitive potassium channel activation by oleoyl-CoA. J Biol Chem 273:26383-26387

51. Fulceri R, Nori A, Gamberucci A, Volpe P, Giunti R, Benedetti A (1994) Fatty acyl-CoA esters induce calcium release from terminal cisternae of skeletal muscle. Cell Calcium 15:109-116

52. Loftus TM, Jaworsky DE, Frehywot GL et al (2000) Reduced food intake and body weight in mice treated with fatty acid synthase inhibitors. Science 288:2379-2381 